\title{
Distance Mesuring of Physical Activity among Students and Workers of Moscow State University of Medicine and Dentistry
}

\author{
Konstantin G. Gurevich ${ }^{1, *}$, Pavel L. Salmanov², Dmitrii A. Pustovalov ${ }^{1}$ \\ ${ }^{1}$ UNESCO Chair, Moscow State University of Medicine and Dentistry, Moscow, 127473, Russia \\ ${ }^{2}$ Chair in medical informatics, Moscow State University of Medicine and Dentistry, Moscow, 127473, Russia
}

\begin{abstract}
Since 2007 Moscow State University of Medicine and Dentistry (MSUMD) uses its own teleconferencing facilities. Distance learning courses on health promotion were started. Electronic textbooks in the field of health promotion were made available. Online questionnaire was design to determine physical activity (PA) which is known to be one of risk factors of development of chronic disease. Methods: 846 students and 144 workers of MSUMD were distance tested to detect their usual PA. Results: The used procedure proved to be valid. PA in women demonstrated to be lower than in men; PA of workers was higher than in students. Additional risk factors (i.e. obesity, smoking) were earlier found in students. Conclusion: Female students might have higher risk of noncommunicable diseases than male students in future due to their low PA. It seems to be higher spread of behavior risk factors among students than workers.
\end{abstract}

Keywords Risk Factor, Physical Activity, Moscow State University of Medicine and Dentistry

\section{Introduction}

Moscow State University of Medicine and Dentistry (MSUMD) is the leading educational institute of high medical education in Russia. It was founded in 1922 as a Dental School. Now it consists of 11 faculties covering all the levels of medical education: medical auxiliaries, general doctors, dentists and postgraduates. About 1400 professors and assistant professors work in MSUMD to teach more than 10000 people.

As the leading medical school MSUMD is involved in health promotion programs. In 2003 UNESCO chair in healthy life for sustainable development was founded. Then International programs for health promotion were translated and country-adapted. Since 2007 teleconferencing studio has been used for lecturing in the sphere of health promotion.

As it is known, noncommunicable diseases (NCDs) are leading in threat of human health and development. Up to $80 \%$ NCDs could be prevented by eliminating the risk factors, mainly physical inactivity, unhealthy diet, tobacco use and harmful use of alcohol. That is why World Health Organization (WHO) determinates monitoring and surveillance of the risk factors as the main component for NCDs prevention[1-2]. This monitoring must be representative, up-to-date

* Corresponding author:

kgurevich@mail.ru (Konstantin G. Gurevich)

Published online at http://journal.sapub.org/ajmms

Copyright (C) 2012 Scientific \& Academic Publishing. All Rights Reserved (modern) and cost-effective[2].

Questionnaires for testing one of the risk factors, usual physical activity (PA), are well-known, and one of those is called International Physical Activity Questionnaires (IPAQ). IPAQ is to provide a number of well-developed instruments that can be used internationally to obtain comparable estimates of physical activity. There are two versions of the questionnaires. The short version is suitable for use in national and regional surveillance systems and the long version provides more detailed information often required in research work or for evaluation purposes[3-5]. Validity of short form has been demonstrated[6]. Earlier we published Russian-adapted version of IPAQ [7] because original questionnaire is design in English.

The propose of this work was to develop distance form or Russian version of IPAQ and use it to find differences in PA between students and workers of MSUMD.

\section{Material and Methods}

After 3 months of intranet free access, results have been analyzed. There were 846 students and 144 workers answered questionnaire, $48 \%$ were female.

Short version of the IPAQ used in work[3-5] earlier, adapted for the Russians[7]. Questionnaire contains 7 questions about usual PA. Variants of possible answers are fixed for automatic analysis, each variant of answer has its own equal in marks. The sum of marks used to receive preliminary results (see below). Internet version of IPAQ was free 
for application in the intranet on site of MSUMD. Users had multiple choice for all questions. For detailed analysis of results we add questions about sex (male, female) and position (student, worker) in the university. Filling of questionnaire was free for intranet-use and does not contain any other personal information.

The test is going in automatically regime and user can receive result in several seconds as a grade of his PA. Level of PA is the sum of marks for each answer of questionnaire. Due to international recommendations[3-5], the user receives results of his testing in three gradations of PA: very low (adynamia), low (hypodynamia), and optimal (normodynamia). The result depends on age and sex. In cases of adynamia and hypodynamia the user also receives recommendations to increase her or his physical activity.

Validity of the used test was proved by Cronbach coefficient [8], Pearson chi-square analysis and standard adjusted residuals calculated to determine sample characteristics. Also we used correlation and regression analysis[9].

The work is approved by local ethic committee of MSUMD.

\section{Results}

The automatic system of PA determination allows to reduce in time for investigation of risk factors for NCDs. It is much more useful for practice medicine. Usually time for filing the questionary did not extend $3 \mathrm{~min}$. Results appeared immediately, in interactive regime. So, our method is timeand cost-effective.

Validity of used test was proved by Cronbach coefficient. In all cases it extended 0.9 (Table 1). Mean coefficient was 0.93 which is corresponding to high level of validity.

It was demonstrated that determined PA of students usually was not optimal (Table 2). In general we can speak about high-level prevalence of hypodynamia and adynamia among students (which are future medical doctors). At least $1 / 3$ of students have adynamia. Only $1 / 3$ of students have optimal PA.

Table 1. Cronbach coefficient.

\begin{tabular}{|c|c|c|}
\hline \multirow{2}{*}{ PA } & \multicolumn{2}{|c|}{ Gender } \\
\cline { 2 - 3 } & Male & Female \\
\hline Students & 0.93 & 0.95 \\
\hline workers & 0.91 & 0.94 \\
\hline
\end{tabular}

Table 2. PA among Students.

\begin{tabular}{|l|c|c|}
\hline \multirow{2}{*}{\multicolumn{1}{|c|}{ PA }} & \multicolumn{2}{c|}{ Gender } \\
\cline { 2 - 3 } & Male & Female \\
\hline Adynamia & $32.0 \%$ & $37.7 \%$ \\
\hline Hypodinamia & $21.5 \%$ & $24.6 \%$ \\
\hline Normodinamia & $46.5 \% *$ & 37.7 \\
\hline
\end{tabular}

$* \mathrm{p}<0.05$ gender difference

Detailed analysis of students' PA demonstrated that (Ta- ble 3) male students have higher mean number of vigorous PA and its duration than female students. For male students it corresponds to that minimal level of PA which is recommended by WHO[2]. For female students it is lower then recommended. Usual duration of walking for male students was also higher than for those female. But both for male and female students it is higher than it is given minimum by WHO[2]. Male students had lower time of sitting during the day. At least there were not found any gender differences between moderate PA and days of walking. Moderated PA corresponds to WHO norms[2].

Table 3. Typical Week PA among Students.

\begin{tabular}{|l|l|l|}
\hline \multirow{2}{*}{ Elements of PA } & \multicolumn{2}{c|}{ Gender } \\
\cline { 2 - 3 } & \multicolumn{1}{|c|}{ Male } & Female \\
\hline $\begin{array}{l}\text { Vigorous PA like digging, aerobic, bicy- } \\
\text { cling during last week (days) }\end{array}$ & $3.0 \pm 0.2^{*}$ & $2.5 \pm 0.3$ \\
\hline Usually spend for vigorous PA (min/day) & $90 \pm 6^{*}$ & $70 \pm 5$ \\
\hline Moderate PA during last week (days) & $3.3 \pm 0.3$ & $3.4 \pm 0.3$ \\
\hline Usually spend for moderate PA (min/day) & $54 \pm 5$ & $60 \pm 5$ \\
\hline Walking during last week (days) & $5.6 \pm 0.2$ & $5.7 \pm 0.2$ \\
\hline Usually walking (min/day) & $74 \pm 5^{*}$ & $64 \pm 5$ \\
\hline Usually sitting (hours/day) & $5.1 \pm 0.2 *$ & $5.6 \pm 0.2$ \\
\hline$*$ p $<0.05$ gender difference & \multicolumn{2}{|l}{} \\
\hline
\end{tabular}

In comparison with students, workers' PA seems to be more optimal (Table 4). For example, men workers have adynamia in 3 times more rarely than men students. Female workers have adynamia in 1.7 times less in frequency then female students. For about $1 / 2$ female workers and $2 / 3$ male workers PA seems to be optimal. But still near $1 / 2$ of workers have adynamia. In general, men have optimal physical activity more often than women.

Table 4. PA among Workers.

\begin{tabular}{|l|c|c|}
\hline \multirow{2}{*}{\multicolumn{1}{|c|}{ PA }} & \multicolumn{2}{|c|}{ Gender } \\
\cline { 2 - 3 } & Male & Female \\
\hline Adynamia & $9.7 \%^{* *}$ & $21.7 \%^{\#}$ \\
\hline Hypodinamia & $12.9 \%^{* \#}$ & $28.3 \%$ \\
\hline Normodinamia & $77,4 \%^{* \#}$ & $50,0 \%{ }^{*}$ \\
\hline \\
* $\mathrm{p}<0.05$ gender difference \\
p $<0.05$ difference between students and workers
\end{tabular}

Detailed analysis of workers' PA demonstrated that (Table 5) female workers had higher vigorous and moderated PA than female students. Sitting time for female workers was lower than for female students. Male workers had lower duration of walking per day than male students and female workers. Moderate PA in male workers was lower than for female workers. But in all cases PA of workers corresponds to those recommended by $\mathrm{WHO}[2]$.

Correlation analysis showed that there is a moderate correlation with $\mathrm{p}<0.05$ between all elements of PA (table 6 ). So, it might be concluded, that people active in one type of PA are usually active in another type of PA. 
Table 6. Significant Correlations between Typical Elements of Week PA.

\begin{tabular}{|l|c|c|c|c|c|c|}
\hline \multicolumn{1}{|c|}{ Elements of PA } & $\begin{array}{c}\text { Usually spend } \\
\text { for vigorous PA } \\
\text { (min/day) }\end{array}$ & $\begin{array}{c}\text { Moderate PA } \\
\text { during last week } \\
\text { (days) }\end{array}$ & $\begin{array}{c}\text { Usually spend for } \\
\text { moderate PA } \\
\text { (min/day) }\end{array}$ & $\begin{array}{c}\text { Walking } \\
\text { during last } \\
\text { week (days) }\end{array}$ & $\begin{array}{c}\text { Usually } \\
\text { walking } \\
\text { (min/day) }\end{array}$ & $\begin{array}{c}\text { Usually } \\
\text { sitting } \\
\text { (hours/day) }\end{array}$ \\
\hline $\begin{array}{l}\text { Vigorous PA like dig- } \\
\text { ging, aerobic, bicycling } \\
\text { during last week (days) }\end{array}$ & 0.53 & 0.36 & 0.37 & 0.27 & 0.31 & -0.38 \\
\hline $\begin{array}{l}\text { Usually spend for vi- } \\
\text { gorous PA (min/day) }\end{array}$ & & & 0.42 & & 0.28 & -0.31 \\
\hline $\begin{array}{l}\text { Moderate PA during last } \\
\text { week (days) }\end{array}$ & & 0.41 & 0.33 & 0.29 & -0.35 \\
\hline $\begin{array}{l}\text { Usually spend for mod- } \\
\text { erate PA (min/day) }\end{array}$ & & & & & 0.43 & -3 \\
\hline $\begin{array}{l}\text { Walking during last } \\
\text { week (days) }\end{array}$ & & & & & & -0.40 \\
\hline $\begin{array}{l}\text { Usually walking } \\
\text { (min/day) }\end{array}$ & & & & & & \\
\hline
\end{tabular}

Table 5. Typical Week PA among Workers.

\begin{tabular}{|l|c|c|}
\hline \multirow{2}{*}{ Elements of PA } & \multicolumn{2}{c|}{ Gender } \\
\cline { 2 - 3 } & Male & Female \\
\hline $\begin{array}{l}\text { Vigorous PA like digging, aerobic, bicy- } \\
\text { cling during last week (days) }\end{array}$ & $3.0 \pm 0.2$ & $3.2 \pm 0.3^{\#}$ \\
\hline Usually spend for vigorous PA (min/day) & $84 \pm 6$ & $80 \pm 6$ \\
\hline Moderate PA during last week (days) & $3.2 \pm 0.3^{*}$ & $3.8 \pm 0.3^{\#}$ \\
\hline Usually spend for moderate PA (min/day) & $52 \pm 6$ & $62 \pm 6$ \\
\hline Walking during last week (days) & $5.5 \pm 0.2$ & $5.1 \pm 0.3$ \\
\hline Usually walking (min/day) & $54 \pm 7^{*}$ & $72 \pm 6^{\#}$ \\
\hline Usually sitting (hours/day) & $4.9 \pm 0.2$ & $5.1 \pm 0.2^{\#}$ \\
\hline \multirow{3}{*}{} \\
$\begin{array}{l}* \\
\text { p }<0.05 \text { gender difference }\end{array} 0.05$ difference between students and workers \\
\hline
\end{tabular}

Earlier we found that more than $20-30 \%$ of students have body mass which extended age norms[10-11]. PA seems to be the main risk factor of obesity development[2-3], and obesity itself is additional risk factor for NCDs[1-2]. In addition up to $60 \%$ of students smoke and $89 \%$ have psychoemotional stress[10]. So, we have to speak about highlevel risk factors prevalenced among students of MSUMD. From another hand workers of MSUMS have lower prevalence of behaviour risk factors for NCDs than students of the same university. From another hand, workers are older than students. It might be assumed that in future today's students will have more spread both of risk factors and NCDs, than present-days adults. And this conclusion is very unfortunate, because it means growth-up costs for medical care system in future.

Our results demonstrated prevalence of behavior with high-risk heath's harmful, mainly in young respondents. Low level of PA with obesity and smoking in young group might result in different health problems in future[2]. Lower level of PA in female (in comparison with male) respondents imply higher risks of osteoporosis and reproductive function[1-2]. The next generation of students probably will be lower health than present. In general, behavior of the main part of students' respondents has been demonstrated to be unhealthy. So, the special programs to increase PA in students have to be design. Such programs should to grow up their vigorous and moderate PA, promote benefits from walking, and reduce sitting time in a day.

\section{Conclusions}

Determination of individual risk factors, for example PA, will allow not only to make up individual health promotion programs, but also to make up individual health screening programs. Nowadays the state program of health screening has differentiation based only on age and sex. But questionnaires designed to assess risk factors will allow make up targeted screening. We prepared automatic version of questionnaire which will be accessible through the Internet. After answering the questions one can receive a description of possible main health problems. Also questionnaire for doctors may be designed. We also are planning to design questionary for determination of nutrition risk factors.

To prevent NCDs development in future complex prophylaxis programs are required. Such programs have to increase physical activity. Female students and workers have to be the most sensitive part of the programs

\section{ACKNOWLEDGEMENTS}

Authors thank Daria D. Stulina for corrections in English. The work is supported by grant of President RF MD1594.2012.7.

\section{REFERENCES}

[1] WHO. 2008-2013 Action Plan for the Global Strategy for the Prevention and Control of Noncommunicable Diseases. Geneva, 2008

[2] WHO. WHO global strategy on diet, physical activity and health: a framework to monitor and evaluate implementation. Geneva, 2008

[3] W. Brown, A. Bauman, T. Chey, S. Trost, and K. Mummery. 
Comparison of surveys used to measure physical activity, Aust. N. Z. J. Public Health, vol 28, pp. 128-134, 2004

[4] W.J. Brown, S. G. Trost, A. Bauman, K. Mummery, and N. Owen. Test-retest reliability of four physical activity measures used in population surveys, J. Sci. Med. Sport, vol. 7, pp. 205-215, 2004

[5] C. Vandelanotte, I. De Bourdeaudhuij, R. Philippaerts, M. Sjöström and J. F. Sallis. Reliability and validity of a computerized and Dutch version of the International Physical Activity Questionnaire (IPAQ), J. Phys. Act. Health, vol. 2, pp. 63-75, 2005

[6] P.H. Lee, D.J. Macfarlane, T.H. Lam, S.M. Stewart. Validity of the International Physical Activity Questionnaire Short Form (IPAQ-SF): A systematic review. Int J Behav Nutr Phys Act. vol 8 (1), pp. 115, 2011

[7] K.G. Gurevich, E.G. Fabrikant. Health promotion, Proffe- sional, Moscow, 2010

[8] D. Westen, R.Rosenthal Improving construct validity: Cronbach, Meehl, and Neurath's ship, Psychol Assess. vol. 17(4), pp.409-412, 2005

[9] R.N. Forthofer, E.S. Lee, M. Hernandez. Biostatistics, Second Edition: A Guide to Design, Analysis and Discovery, 2 edition, Ac,.mic Press, USA, 2006

[10] K.G. Gurevich, K.I. Aksenova, V.P. Degtyarev, A.N. Kazulin, N.V. Klimina, N.D. Konorov, E.M. Kuz'mina, I.V. Maev, U.V. Martynov, V.U. Mishin, E.V. Orestova, L.F. Panchenko, S.A. Popkov, S.N. Postugalov, D.A. Pustovalov, E.G. Fabrikant, Introduction into healthy life style, MSUMD, Moscow, 2005

[11] D.N.Gasina, K.G.Gurevich Obesity in Moscow school age students: prevalence, age-and gender-related features. Food and Public Health, vol 1. pp. 1-5, 2011 